\title{
VALIDITY OF SELF-REPORTING OF GAIT ALTERATION AFTER TAP TEST AMONG PATIENTS WITH IDIOPATHIC NORMAL PRESSURE HYDROCEPHALUS
}

original paper

() Wroclaw University of Health and Sport Sciences

DOI: https://doi.org/10.5114/hm.2021.103291

\section{SUNEE BOVONSUNTHONCHAI ${ }^{1}$, THEERAPOL WITTHIWEJ ${ }^{2}$, ROONGTIWA VACHALATHITI ${ }^{1}$, SITH SATHORNSUMETEE ${ }^{3}$, CHANON NGAMSOMBAT ${ }^{4}$, ORASA CHAWALPARIT ${ }^{4}$, WEERASAK MUANGPAISAN ${ }^{5}$}

\author{
${ }^{1}$ Faculty of Physical Therapy, Mahidol University, Nakhon Pathom, Thailand \\ ${ }^{2}$ Division of Neurosurgery, Department of Surgery, Faculty of Medicine Siriraj Hospital, Mahidol University, Bangkok, \\ Thailand \\ ${ }^{3}$ Division of Neurology, Department of Medicine, Faculty of Medicine Siriraj Hospital, Mahidol University, Bangkok, \\ Thailand; NANOTEC-Mahidol University Center of Excellence in Nanotechnology for Cancer Diagnosis and Treatment, \\ Faculty of Medicine Siriraj Hospital, Mahidol University, Bangkok, Thailand \\ ${ }^{4}$ Department of Radiology, Faculty of Medicine Siriraj Hospital, Mahidol University, Bangkok, Thailand \\ ${ }^{5}$ Department of Preventive and Social Medicine, Faculty of Medicine Siriraj Hospital, Mahidol University, Bangkok, Thailand
}

\begin{abstract}
Purpose. The study aimed to examine the validity of self-reporting as an additional method to indicate gait alteration among patients with idiopathic normal pressure hydrocephalus. The score from self-reporting of gait alteration was validated with the data obtained from gait pressure measuring plate. In addition, temporo-spatial gait parameters among 3 groups classified by overall gait improvement (no change, slight, and good) were compared.

Methods. This study employed a cross-sectional design and investigated 31 patients with idiopathic normal pressure hydrocephalus. Gait performance was determined by a gait pressure measuring plate before and 24 hours after a tap test. Patients rated the changed score for gait behaviours using a questionnaire once on the day after the tap test. Criterion validity of the changed scores from patients' self-reporting and data from the gait pressure measuring plate was examined. In addition, temporo-spatial gait parameters were compared among 3 groups with one-way analysis of variance and the Bonferroni posthoc test to determine pairwise difference.

Results. Significant correlations were found for the temporo-spatial gait parameters between data from self-reporting and the gait pressure measuring plate. Comparisons of temporo-spatial gait parameters among groups demonstrated significant differences in all parameters.

Conclusions. Gait alteration identified by self-reporting was valid with gait performance measured by the gait pressure measuring plate. To achieve timely and appropriate medical management, we recommend health care professionals to request patients and caregivers to recognize gait alterations in assisting the disease progression identification.
\end{abstract}

Key words: gait, normal pressure hydrocephalus, self-report, spinal puncture

\section{Introduction}

Idiopathic normal pressure hydrocephalus (iNPH) is an important cause of a clinical triad which consists of gait disturbance, dementia, and urinary disturbance [1]. The iNPH has no precipitating cause and its definitive incidence remains unknown [2]. The patho- physiology of iNPH is still obscure and usually links to the cause of a decreased cerebrospinal fluid (CSF) absorption in the brain [3]. Moreover, in a large proportion of patients, iNPH remains either undiagnosed or misdiagnosed $[4,5]$. The iNPH is recognized as a treatable disease but delayed or erroneous diagnosis could lead to other complications or irreversibility when

Correspondence address: Sunee Bovonsunthonchai, 999 Phuttamonthon 4 Rd., Salaya, Phuttamonthon, Nakhon Pathom, 73170, Thailand, e-mail: sunee.bov@mahidol.edu

Received: December 23, 2019

Accepted for publication: August 6, 2020

Citation: Bovonsunthonchai S, Witthiwej T, Vachalathiti R, Sathornsumetee S, Ngamsombat C, Chawalparit O, Muangpaisan W. Validity of self-reporting of gait alteration after tap test among patients with idiopathic normal pressure hydrocephalus. Hum Mov. 2022;23(1):96-104; doi: https://doi.org/10.5114/hm.2021.103291. 
severe damage occurs to larger brain areas [4]. Depression complicated by hydrocephalus was reported in a case study of a patient who was undiagnosed, but the symptoms recovered after treatment with CSF drainage and appropriate antidepressant [6]. Hence, early diagnosis and proper management contribute to a significant reduction of symptoms and are crucial to lowering the cost of medical care [5, 7]. Although radiography has developed and is widely used as the referenced diagnosis method, clinical diagnostic criteria remain the most important element in iNPH diagnosis [7].

Among clinical diagnostic criteria, gait disturbance was the most frequently observed change (in approximately $77.7 \%$ of patients) [8]. In a study by Toma et al. [9], gait was also considered the most important problem by both patients and caregivers. The occurrence of gait disturbance among individuals with iNPH is caused by subcortical motor control dysfunction rather than primary pyramidal tract imbalance [10]. Abnormal characteristics in patients with iNPH usually include hypokinetic, shuffling, magnetic, and wide-based gait [11-13]. Changes in gait parameters comprise decreased gait speed, stride length, and step height, as well as increased step width and foot angle [14-18]. An explanation of the improved gait parameters after a tap test may be supported by a previous exploratory imaging study which demonstrated that patients with iNPH who responded to a tap test had lower values of CSF flow than the ones who did not respond [19]. Among the clinical triad being assessed, changes in gait were indicated as the most favourable parameter in diagnosis and shunt effectiveness prediction [20,21]. Clinical and instrumental gait measurements provide beneficial evidence to detect progression. Gait improvements after a tap test among patients with iNPH may include increased gait speed [12, 21-23], increased stride length $[12,14,23]$, and decreased time spent while walking over the distance [24, 25]. In addition, changes in quality of life and/or in clinical triad components are usually monitored and set as important outcomes. The determination of whether the patient is responding to the treatment or not often depends on the therapist's judgment, patient self-reporting, and findings from several clinical assessments related to the individual problems of the patient.

The self-monitoring procedure, in which the patients observe their changing conditions of interest, offers a potential advantage to allow patients or caregivers to monitor their symptoms more frequently [26]. However, salient threats to the reliability of this information may include misinterpretation, memory problems, and poor motivation and compliance [26]. To re-evaluate management for this patient population, symptom reports from patients and caregivers are crucial. Therefore, reports concerning altered gait function need to be validated. The aim of the study was to examine the validity of self-reporting in gait alteration among patients with iNPH. In addition, gait parameters among classified groups of improvement (no change, slight, and good) were compared. We hypothesized that selfreporting of gait alteration was feasible and valid enough to be used as a tool to detect gait performance after a tap test among patients with iNPH.

\section{Material and methods}

\section{Participants}

Neurologists or neurosurgeons diagnosed iNPH in patients in accordance with the clinical guidelines of the Japanese Society of Normal Pressure Hydrocephalus [27]. Inclusion criteria involved iNPH symptoms, age of 60 years or more, presence of at least one of the clinical triad symptoms (gait disturbance, cognitive impairment, urinary incontinence), ventriculomegaly assessed by magnetic resonance imaging, CSF pressure of $200 \mathrm{~mm} \mathrm{H}_{2} \mathrm{O}$ or less and normal CSF content, and ability to walk at least $6 \mathrm{~m}$ with or without using a device or assistance. Participants were excluded from the study when they were unable to follow the instructions or to complete data collection. Prior to data collection, all patients were informed about the study details. Data were collected from November 2015 to January 2017 at the Laboratory for Gait and Mobility Analysis, Division of Neurology, Department of Medicine, Faculty of Medicine Siriraj Hospital, Mahidol University.

Construction of the self-reporting questionnaire of gait alteration

Six questions of the self-reporting questionnaire of gait alteration were initially constructed; they referred to the common gait deviations presented by patients with iNPH $[14,28]$. Gait alterations after the tap test were rated by patients and caregivers. The questions included (1) overall gait, (2) step length, (3) step time, (4) gait speed, (5) foot angle, and (6) stance time. However, the last 2 questions (foot angle and stance time) were finally excluded because most patients were unable to identify the change of foot placement and the time spent during walking. Thus, the 
other 4 questions were used to determine the criterion-related validity with gait data tracking from a gait pressure measuring plate (Appendix A).

Owing to the impaired cognitive function in patients with iNPH, the assessors requested both patients and caregivers to memorize how the patients walked on the day before the tap test and they were asked about gait changes again 24 hours after the tap test.

\section{Instrumentation}

The objective gait parameters were obtained with a Zebris Force Distribution Measurement (FDM) platform (dimensions: $307 \times 60.5 \times 2.1 \mathrm{~cm}[\mathrm{~L} \times \mathrm{W} \times \mathrm{H}]$, Germany) with a sampling frequency of $100 \mathrm{~Hz}$, synchronized by a camera. The system automates the acquisition, analysis, and reporting of the objective temporo-spatial gait parameters using the WinFDM software. The initial contact and toe-off events were determined from pressure sensors while the feet touched and lifted off the platform. Gait data were tracked in the middle part of the FDM platform. The parameters included step length, step time, stride length, stride time, cadence, and gait speed. Step length and step time were averaged from the left and right sides. Stride length and stride time were derived from one gait cycle.

\section{Protocol}

Gait parameters were collected by using a gait pressure measuring plate before the tap test and 24 hours after the tap test. Each patient underwent a spinal tap procedure, during which neurosurgeons removed $30-50$ cc of CSF by lumbar puncture. The self-reporting questionnaire was used to detect any alteration of gait between the pre- and post-tap-test status. To reduce errors when collecting the data, the same demonstration and instructions for gait assessment were provided, i.e., 'please walk at your usual comfortable speed'. The participants walked with bare feet on a 3-m platform at a comfortable self-selected gait speed for 2-3 trials, depending on their performance. Averaged gait parameters from 2 successful trials were used in further analysis. For safety, a physiotherapist walked alongside each patient to assist or guard when needed.

\section{Criterion validity and effect size}

Criterion validity of the self-reporting of gait alteration was examined with the changed scores (the different values between pre- and post-tap-test status) obtained from the gait pressure measuring plate by using Spearman's correlation coefficient $\left(r_{\mathrm{s}}\right)$. Values of $0.20,0.40,0.60$, and 0.80 were applied to represent weak, moderate, strong, and very strong relationships, respectively [29].

\section{Power estimation}

The main objective of the study was to investigate the criterion validity of the self-reporting of gait alteration with data obtained from the gait pressure measuring plate. The correlation coefficient was used to determine the relationship between the data from these 2 methods. The general recommendation for the sample size in the criterion validity study was at least 30 and not more than 500. Because the overall number of subjects was 31, the significant correlation coefficient was expressed around 0.48-0.67. The power of the study was re-evaluated with the $G^{*}$ Power software, version 3.1.9.2, with the exact test, post-hoc method, and alpha level set at 0.05 . The power of the study was achieved at 0.80 and 0.99 , according to the values of the correlation coefficient.

\section{Statistical analyses}

IBM SPSS software, version 20 (IBM Corp., USA) was used for all data analyses, and descriptive statistics were applied to determine the participants' characteristics. Normality was investigated with the Kolmogorov-Smirnov goodness of fit test, which demonstrated normal distribution. Correlations between the selfreporting in gait alteration rated by patients and caregivers on the day after the tap test and the changed score obtained from the gait pressure measuring plate on the pre- and post-tap-test days were determined by using Spearman's rho $\left(r_{\mathrm{s}}\right)$. Comparisons of gait parameters among the 3 groups of improvement in overall gait ability (no change, slight, and good) perceived by patients and caregivers were determined with the one-way analysis of variance. The Bonferroni post-hoc test served to determine the differences between groups. All data were tested with statistical significance set at $p<0.05$.

\section{Ethical approval}

The research related to human use has complied with all the relevant national regulations and institutional policies, has followed the tenets of the Declaration of Helsinki, and has been approved by the authors' institutional review board or an equivalent committee. 


\section{Informed consent}

Informed consent approved by the institutional review board (COA No.: SI 340/2014) has been obtained from all individuals included in this study.

\section{Results}

Overall, 36 patients with iNPH were recruited in the study; 5 were excluded because of gout attack $(n=1)$, feeling exhausted on the post-tap-test day $(n=2)$, and impossibility to extract data from a very short step length $(n=2)$. Thus, only 31 participants remained in the study. Their characteristics are presented in Table 1 . The number of the subjects who rated for the items of the self-reporting of gait alteration is illustrated in Figure 1. Of the total of 31 participants, only 1 reported a decrease in step time. A certain number of patients reported no change for the step length $(n=14)$, step time $(n=11)$, gait speed $(n=10)$, and overall gait $(n=8)$. Many respondents reported gait improvement of small to great extents after the tap test for the step length $(n=17)$, step time $(n=19)$, gait speed $(n=21)$, and overall gait $(n=23)$.
Table 1. Characteristics of the participants $(n=31)$

\begin{tabular}{ll}
\hline Parameters & Values (mean $\pm S D$, or $[n]$ ) \\
\hline Age (years) & $78.10 \pm 9.70$ \\
Sex $(n)$ & Female (14) \\
& Male (17) \\
Weight (kg) & $60.18 \pm 8.85$ \\
Height (cm) & $160.23 \pm 9.70$ \\
iNPH onset (months) & $22.37 \pm 6.66$ \\
MMSE-Thai 2002 (score) & $14.97 \pm 5.98$ \\
Gait aids usually used & None (17) \\
in daily life (n) & Cane (7) \\
& Walker (7) \\
Assistance required & None or under supervision (16) \\
when walking $(n)$ & Mild assist (8) \\
& Moderate assist (6) \\
& Maximal assist (1) \\
\hline
\end{tabular}

iNPH - idiopathic normal pressure hydrocephalus, MMSE - Mini-Mental State Examination

* incomplete data $(n=29)$
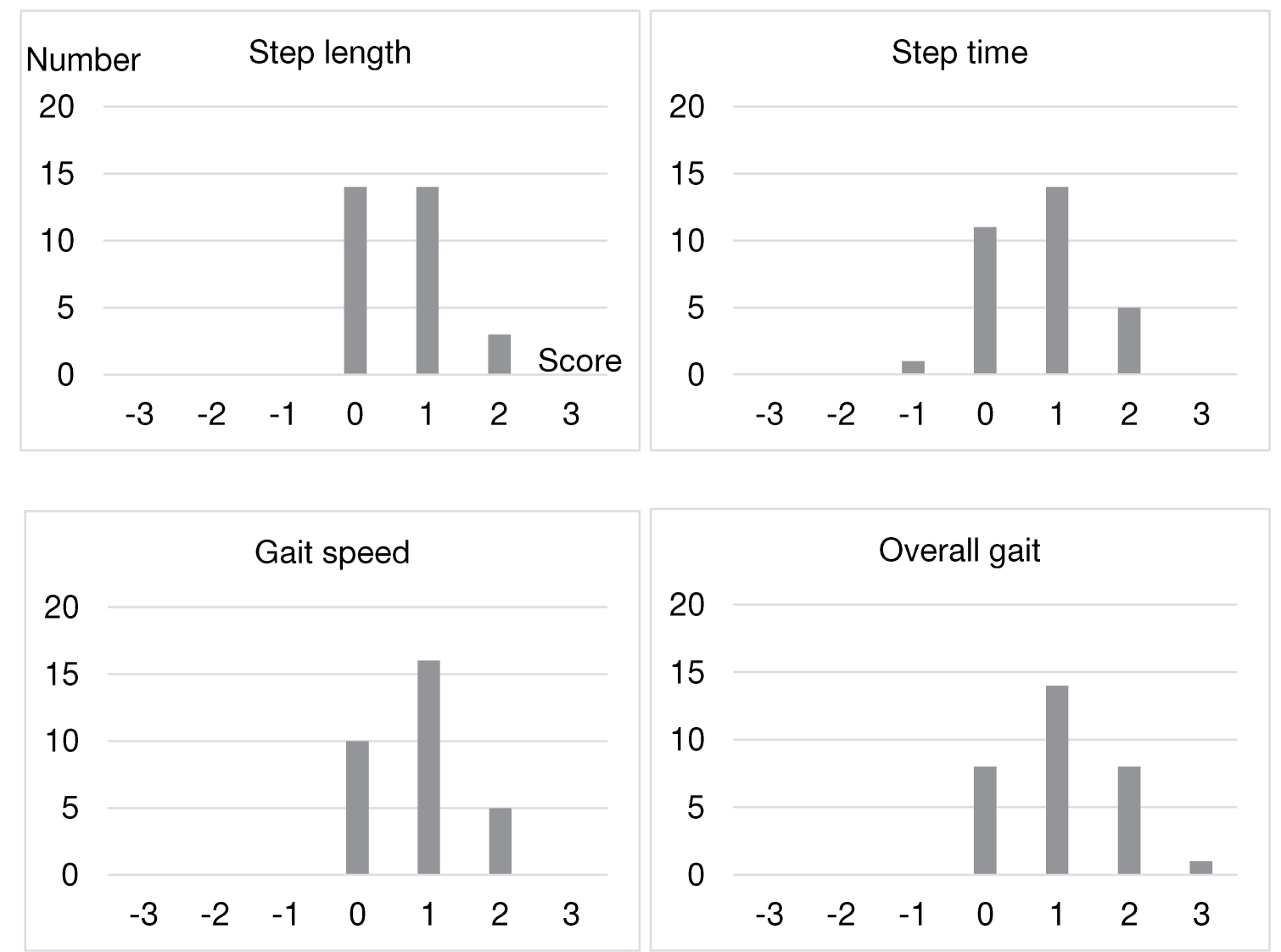

Figure 1. Number of participants rating for the items of the self-reporting of gait alteration after spinal tap test (-3: extremely worsened/decreased, -2: much worsened/decreased, -1 : little worsened/decreased), 0: no change, 1: little improved/increased, 2: much improved/increased, 3: extremely improved/increased) 


\section{HUMAN MOVEMENT}

S. Bovonsunthonchai et al., Gait in idiopathic normal pressure hydrocephalus patients

Table 2. Correlations between data from the self-report and from the gait pressure measuring plate $(n=31)$

\begin{tabular}{lccccccc}
\hline \multirow{2}{*}{ Self-report } & & \multicolumn{6}{c}{ Data from the gait pressure measuring plate } \\
\cline { 2 - 7 } & & Step length & Step time & Stride length & Stride time & Cadence & Gait speed \\
\hline \multirow{2}{*}{ Step length } & $r_{s}$ & 0.352 & $-0.535^{*}$ & 0.354 & $-0.524^{*}$ & $0.610^{*}$ & $0.542^{*}$ \\
& $p$ & 0.052 & 0.002 & 0.051 & 0.002 & $<0.001$ & 0.002 \\
\hline \multirow{2}{*}{ Step time } & $r_{s}$ & $0.500^{*}$ & $-0.490^{*}$ & $0.496^{*}$ & $-0.486^{*}$ & $0.540^{*}$ & $0.590^{*}$ \\
\hline \multirow{2}{*}{ Gait speed } & $p$ & 0.004 & 0.005 & 0.005 & 0.006 & 0.002 & $<0.001$ \\
\hline \multirow{2}{*}{ Overall gait } & $r_{s}$ & $0.494^{*}$ & $-0.623^{*}$ & $0.483^{*}$ & $-0.629^{*}$ & $0.706^{*}$ & $0.670^{*}$ \\
& $p$ & 0.005 & $<0.001$ & 0.006 & $<0.001$ & $<0.001$ & $<0.001$ \\
\hline
\end{tabular}

Statistical significance tested by Spearman's rho $\left(r_{\mathrm{s}}\right)$

* correlation significant at $p<0.01$

Table 3. Comparison of the changed score of gait parameters among different groups of participants

\begin{tabular}{|c|c|c|c|c|}
\hline \multirow[b]{2}{*}{ Gait parameters } & \multicolumn{3}{|c|}{ Groups of improvement } & \multirow[b]{2}{*}{$p$} \\
\hline & $\begin{array}{l}\text { No change } \\
\quad(n=8)\end{array}$ & $\begin{array}{l}\text { Slight improvement } \\
\qquad(n=14)\end{array}$ & $\begin{array}{l}\text { Good improvement } \\
\qquad(n=9)\end{array}$ & \\
\hline Step length (cm) & $-1.98 \pm 3.03$ & $-0.24 \pm 2.07$ & $2.95 \pm 2.47$ & 0.001 \\
\hline Step time (s) & $0.03 \pm 0.11$ & $-0.02 \pm 0.04$ & $-0.08 \pm 0.06$ & 0.010 \\
\hline Stride length (cm) & $-4.13 \pm 6.57$ & $-0.24 \pm 4.35$ & $6.08 \pm 4.64$ & 0.001 \\
\hline Stride time (s) & $0.07 \pm 0.21$ & $-0.03 \pm 0.10$ & $-0.15 \pm 0.11$ & 0.007 \\
\hline Cadence (steps/min) & $-5.92 \pm 16.98$ & $2.01 \pm 5.17$ & $9.19 \pm 4.67$ & 0.011 \\
\hline Gait speed $(\mathrm{km} / \mathrm{h})$ & $-0.24 \pm 0.31$ & $0.02 \pm 0.15$ & $0.28 \pm 0.18$ & $<0.001$ \\
\hline
\end{tabular}

Significance tested by one-way analysis of variance at $p<0.05$

Correlation between the self-reporting and the changed score from gait pressure measuring plate

Data from the self-reporting rating by patients and caregivers on the post-tap-test day were correlated with the changed score of gait parameters detected by the gait pressure measuring plate (Table 2). Almost all parameters significantly correlated, except for correlations of step length from self-reporting and step length from gait pressure measuring plate data $\left(r_{\mathrm{s}}=\right.$ $0.352, p=0.052$ ), and step length from self-reporting and stride length from gait pressure measuring plate data $\left(r_{\mathrm{s}}=0.354, p=0.051\right)$.

Comparison of the changed scores of temporo-spatial gait parameters among different groups of improvement

Patients with iNPH were classified into 3 groups in accordance with the overall gait improvement perceived by patients and caregivers on the post-tap-test day. Eight participants reported no change, 14 indicated slight improvements, and 9 pointed at significant improvements. Therefore, 3 classification groups were set: no change, slight improvement, and good improvement.

Comparisons of temporo-spatial gait parameters among these 3 groups are reported in Table 3. Significant differences were found among the 3 groups of participants in all gait parameters $(p<0.05)$. By using the Bonferroni post-hoc analysis, significant differences were determined for step length between the no-change and good improvement groups $(p=0.001)$ and between the slight and good improvement groups ( $p=0.015)$, whereas no significant difference was observed between the no-change and slight improvement groups $(p=0.366)$. For the step time, a significant difference was found between the no-change and good improvement groups $(p=0.008)$, but not between the no-change and slight improvement groups $(p=0.354)$ or between the slight and good improvement groups $(p=0.146)$. For the stride length, significant differences were established between the no-change and good im- 
provement groups ( $p=0.001)$ and between the slight and good improvement groups ( $p=0.021$ ), but not between the no-change and slight improvement groups $(p=0.284)$. For the stride time, a significant difference was found between the no-change and good improvement groups $(p=0.006)$, but not between the nochange and slight improvement groups $(p=0.346)$ or between the slight and good improvement groups $(p=0.111)$. For the cadence, a significant difference was observed between the no-change and good improvement groups ( $p=0.009)$ but not between the nochange and slight improvement groups $(p=0.212)$ or between the slight and good improvement groups ( $p=0.266$ ). Additionally, gait speed demonstrated significant differences between the no-change and slight improvement groups ( $p=0.024)$, between the no-change and good improvement groups $(p<0.001)$, and between the slight and good improvement groups $(p=0.021)$.

\section{Discussion}

For the self-reporting, we constructed the questionnaire with brief questions referring to gait deviations in patients with iNPH. This method followed the recommendations for designing and administering questionnaires, which should focus only on the data necessary to plan the analysis [30]. Also, lengthy or complicated questionnaires may create a burden in routine clinical use. Response burden has been reported as a result of low response rate, and reduced questionnaire completion and data quality. The burden may be particularly problematic for specific populations such as the elderly, children, and individuals with illnesses [31]. Therefore, at present, questionnaires are constructed to use a short form. In order for the patients to remember the alteration of gait characteristics, the questionnaire items focused on simple gait parameters, such as time, distance, and speed. The self-reporting of gait alteration was rated on a 7-item scale, as shown in Appendix A. This scale helped the patients to realize their gait changes in the direction of improving or worsening only. It could not provide values of gait parameters, so therapists should measure objective gait data concurrently. However, some initial questions were removed because of the difficulty in rating the changes. As a result of cognitive impairment, being one of the cardinal signs among these patients, the number of questions was reduced to make the questionnaire easier.

Another point of importance was the period before rating the change in gait by the participants. We re- quested all patients and caregivers to recognize the gait performance on the day before the tap test and asked them to rate the changes 24 hours after the tap test. Although the self-reporting in gait alteration was created to be straightforward and had a good correlation with the objective gait measurement outcomes, the process of self-monitoring requires confidence that the instruction was properly explained to the participants. Salient threats may also include memory problems and poor motivation or compliance [26].

\section{Correlation between the self-reporting} and the changed score from gait pressure measuring plate

The correlation between the data from self-reporting and the gait pressure measuring plate allowed us to ensure that the patients' self-monitoring of gait alteration was valid. Thus, therapists should advise patients and their caregivers on the importance of being aware of any changes in walking. The results of this study demonstrated that information from patients with iNPH was valid and consistent with the data obtained from the gait pressure measuring plate. This subjective information could assist therapists to better design and manage further treatment. Only one related study investigated the relationship between perceived and measured changes in walking among stroke patients. Before and after a 3-month exercise program, perceived changes were assessed by using a 15-point scale and measured changes were determined with the 6-minute walk test, at self-paced and fast-paced gait speeds. The results demonstrated a moderate level of correlation between the perceived and the measured changes. However, no correlations between measured and perceived changes in self- and fast-paced gait speeds were observed [32].

Patients' self-reporting evaluation of gait alteration after a tap test with an objective gait measurement was performed in a previous study [21]. However, a false-positive result was found in up to $83 \%$ and almost $67 \%$ of true positive results were reported. The difference between the study findings may relate to the criteria used for determining responders and nonresponders by the objective gait measurement with a 20\% increase or decrease of gait speed after the tap test compared with the status before the tap test. The self-reporting consisted in patients' indicating 'yes' or 'no' for the feeling of gait improvement after the tap test. Owing to the different data collections and analyses between studies, the present study investigated almost all correlations of the self-rating in gait alteration 
with the data obtained by the gait pressure measuring plate. The perceived change rated by patients on step length and stride length showed no correlation with data from the gait pressure measuring plate. This may be caused by difficulty in recognizing or a greater variability of distance compared with temporal parameters [33].

\section{Comparison of the changed scores}

of temporo-spatial gait parameters

among different groups of improvement

The participants were classified into 3 groups of improvement based on overall gait performance: no change, slight, and good groups. Obvious differences in gait parameters were observed among the groups. After the tap test, the good improvement group demonstrated that all gait parameters had improved, with increased step length, stride length, cadence, and gait speed, as well as decreased step time and stride time. The slight improvement group presented decreased step and stride times and increased cadence and gait speed, with minimally decreased step and stride lengths. The no-change group revealed a tendency of worsening in all gait parameters. In general, patients with iNPH could be categorized as responders and nonresponders to the treatment [19, 21, 28]. Classification is usually evaluated by observation from doctors accompanied by feedbacks from patients and caregivers. However, patients who experience no change or obscured alteration (unable to indicate improving or worsening of the symptoms) may be classified as non-responders.

The treatment results in iNPH may be influenced by comorbidities, delayed diagnosis, and/or inappropriate management, contributing to complications and difficulties to resolve [4-6, 34]. However, the pathogenesis of this disease is not yet clearly understood and is suggested to be related to the CSF drainage system [3]. Gait has been demonstrated as one of the important sensitive outcomes of the tap test and is usually used as the key identifier for prognosis [20]. Nevertheless, the improvement of gait could be confounded with the aspect of assessing time. A previous study by Schniepp et al. [21] demonstrated that the maximum improvement of gait speed occurred 1-2 days after the tap test and the maximum gait parameters assessed with the dual task appeared 2-3 days after the tap test. Gallagher et al. [35] evaluated gait speed using a 10-m walk test $2-4$ hours after the tap test in iNPH patients. They found a significant increase in gait speed of $0.08 \mathrm{~m} / \mathrm{s}$ in responders as compared with non-re- sponders. In the present study, we observed a greater improvement of gait speed $(0.52 \mathrm{~km} / \mathrm{h}$ or $0.14 \mathrm{~m} / \mathrm{s})$ in the good group than in the no-change group. For the other gait parameters, the good group showed increased step length of $2.95 \mathrm{~cm}$, decreased step time of $0.08 \mathrm{~s}$, increased cadence of $9.19 \mathrm{steps} / \mathrm{min}$, and increased gait speed of $0.28 \mathrm{~km} / \mathrm{h}(0.08 \mathrm{~m} / \mathrm{s})$ when compared with the no-change group. Unfortunately, there is no previous report regarding the significant clinical change in iNPH. The minimal detectable change with a 95\% confident interval (MDC95) of $0.10 \mathrm{~m} / \mathrm{s}$ was shown to be clinically significant in low gait capacity stroke patients (the ones who walked slower than $0.4 \mathrm{~m} / \mathrm{s}$ ) [36] and the minimal detectable change with a $90 \%$ confident interval (MDC90) of $9.4 \mathrm{~cm} / \mathrm{s}(0.094 \mathrm{~m} / \mathrm{s})$ of gait speed was reported for patients with Alzheimer disease [37]. In addition, MDC95 for the step time of $0.042 \mathrm{~s}$ and for the step length of $0.047 \mathrm{~m}$ were observed in the elderly [38]. Therefore, it can be difficult to conclude whether such a change reaches the level of clinical change or not, as there is no relevant database in iNPH. Another point which should be taken into consideration may include the extent of data deviation.

This study may have a limitation with the other 2 factors of the clinical triad not being determined. Monitoring of the change in gait over a period longer than 1 day should be studied and a greater sample is needed in future.

\section{Conclusions}

This study demonstrated that the self-reporting of gait alteration was valid with the results obtained by using a gait pressure measuring plate. To achieve timely and appropriate medical management, we recommend health care professionals to request patients and caregivers to recognize gait alterations in assisting the disease progression identification.

\section{Acknowledgements}

This study was funded by the Faculty of Physical Therapy and Faculty of Medicine Siriraj Hospital, Mahidol University.

\section{Disclosure statement}

No author has any financial interest or received any financial benefit from this research.

\section{Conflict of interest}

The authors state no conflict of interest. 


\section{References}

1. Hakim S, Adams RD. The special clinical problem of symptomatic hydrocephalus with normal cerebrospinal fluid pressure. Observations on cerebrospinal fluid hydrodynamics. J Neurol Sci. 1965;2(4):307-327; doi: 10.1016/0022-510x(65)90016-x.

2. Graff-Radford NR. Normal pressure hydrocephalus. Neurol Clin. 2007;25(3):809-832, vii-viii; doi: 10.1016/ j.ncl.2007.03.004.

3. Bräutigam K, Vakis A, Tsitsipanis C. Pathogenesis of idiopathic normal pressure hydrocephalus: a review of knowledge. J Clin Neurosci. 2019;61:10-13; doi: 10.1016/j.jocn.2018.10.147.

4. Siedlecki SL. Normal pressure hydrocephalus: are you missing the signs? J Gerontol Nurs. 2008;34(2):2733; doi: 10.3928/00989134-20080201-11.

5. Nassar BR, Lippa CF. Idiopathic normal pressure hydrocephalus: a review for general practitioners. Gerontol Geriatr Med. 2016;2:2333721416643702; doi: $10.1177 / 2333721416643702$.

6. Urban M, Rabe-Jabłońska J. Undiagnosed normal pressure hydrocephalus as a cause of diagnostic difficulties in a patient with depression. J Psychiatr Pract. 2013;19(6):501-504; doi: 10.1097/01.pra.0000438191. 04786.5f.

7. Baltatanu D, Berteanu M. Idiopathic normal pressure hydrocephalus - what we know. Maedica. 2019;14(2): 161-164; doi: 10.26574/maedica.2019.14.2.161.

8. Kuriyama N, Miyajima M, Nakajima M, Kurosawa M, Fukushima W, Watanabe Y, et al. Nationwide hospital-based survey of idiopathic normal pressure hydrocephalus in Japan: epidemiological and clinical characteristics. Brain Behav. 2017;7(3):e00635; doi: 10.1002/ brb3.635.

9. Toma AK, Tarnaris A, Kitchen ND, Watkins LD. Working towards patient oriented outcome assessment in normal pressure hydrocephalus, what is the most important? Acta Neurochir. 2011;153(1):177-180; doi: 10.1007/s00701-010-0781-8.

10. Rosseau G. Normal pressure hydrocephalus. Dis Mon. 2011;57(10):615-624; doi: 10.1016/j.disamonth.2011. 08.023 .

11. Marmarou A, Black P, Bergsneider M, Klinge P, Relkin N, International NPH Consultant Group. Guidelines for management of idiopathic normal pressure hydrocephalus: progress to date. Acta Neurochir Suppl. 2005;95:237-240; doi: 10.1007/3-211-32318-x_48.

12. Bugalho P, Guimarães J. Gait disturbance in normal pressure hydrocephalus: a clinical study. Parkinsonism Relat Disord. 2007;13(7):434-437; doi: 10.1016/j. parkreldis.2006.08.007.

13. Nowak DA, Topka HR. Broadening a classic clinical triad: the hypokinetic motor disorder of normal pressure hydrocephalus also affects the hand. Exp Neurol. 2006; 198(1):81-87; doi: 10.1016/j.expneurol.2005.11.003.

14. Stolze H, Kuhtz-Buschbeck JP, Drücke H, Jöhnk K, Diercks C, Palmié S, et al. Gait analysis in idiopathic normal pressure hydrocephalus - which parameters respond to the CSF tap test? Clin Neurophysiol. 2000; 111(9):1678-1686; doi: 10.1016/s1388-2457(00)00362-x.

15. Relkin N, Marmarou A, Klinge P, Bergsneider M, Black PM. Diagnosing idiopathic normal-pressure hydrocephalus. Neurosurgery. 2005;57(3 Suppl.):4-16; doi: 10.1227/01.neu.0000168185.29659.c5.

16. Kuba H, Inamura T, Ikezaki K, Inoha S, Nakamizo A, Shono T, et al. Gait disturbance in patients with low pressure hydrocephalus. J Clin Neurosci. 2002;9(1): 33-36; doi: 10.1054/jocn.2001.1010.

17. Soelberg Sørensen P, Jansen EC, Gjerris F. Motor disturbances in normal-pressure hydrocephalus. Special reference to stance and gait. Arch Neurol. 1986;43(1): 34-38; doi:10.1001/archneur.1986.00520010030016.

18. Stolze H, Kuhtz-Buschbeck JP, Drücke H, Jöhnk K, Illert M, Deuschl G. Comparative analysis of the gait disorder of normal pressure hydrocephalus and Parkinson's disease. J Neurol Neurosurg Psychiatry. 2001; 70(3):289-297; doi: 10.1136/jnnp.70.3.289.

19. Gallagher R, Bateman G, Marquez J, Osmotherly P. Are gait changes linked to CSF flow changes in the sagittal sinus? Neuroradiology. 2019;61(6):659-666; doi: 10.1007/s00234-019-02192-2.

20. Ishikawa M, Yamada S, Yamamoto K. Early and delayed assessments of quantitative gait measures to improve the tap test as a predictor of shunt effectiveness in idiopathic normal pressure hydrocephalus. Fluids Barriers CNS. 2016;13(1):20; doi: 10.1186/s12987016-0044-z.

21. Schniepp R, Trabold R, Romagna A, Akrami F, Hesselbarth K, Wuehr M, et al. Walking assessment after lumbar puncture in normal-pressure hydrocephalus: a delayed improvement over 3 days. J Neurosurg. 2017; 126(1):148-157; doi: 10.3171/2015.12.JNS151663.

22. Ravdin LD, Katzen HL, Jackson AE, Tsakanikas D, Assuras S, Relkin NR. Features of gait most responsive to tap test in normal pressure hydrocephalus. Clin Neurol Neurosurg. 2008;110(5):455-461; doi: 10.1016/ j.clineuro.2008.02.003.

23. Bugalho P, Alves L, Miguel R. Gait dysfunction in Parkinson's disease and normal pressure hydrocephalus: a comparative study. J Neural Transm. 2013; 120(8):1201-1207; doi: 10.1007/s00702-013-0975-3.

24. Abram K, Bohne S, Bublak P, Karvouniari P, Klingner CM, Witte OW, et al. The effect of spinal tap test on different sensory modalities of postural stability in idiopathic normal pressure hydrocephalus. Dement Geriatr Cogn Dis Extra. 2016;6(3):447-457; doi: 10.1159/000 450602.

25. Bovonsunthonchai S, Witthiwej T, Ngamsombat C, Sathornsumetee S, Vachalathiti R, Muangpaisan W, et al. Effect of spinal tap test on the performance of sitto-stand, walking, and turning in patients with idiopathic normal pressure hydrocephalus. Nagoya J Med Sci. 2018;80(1):53-60; doi: 10.18999/nagjms.80.1.53. 


\section{HUMAN MOVEMENT}

S. Bovonsunthonchai et al., Gait in idiopathic normal pressure hydrocephalus patients

26. Montgomery GK, Reynolds NC Jr. Compliance, reliability, and validity of self-monitoring for physical disturbances of Parkinson's disease. The Parkinson's Symptom Diary. J Nerv Ment Dis. 1990;178(10):636641; doi: 10.1097/00005053-199010000-00004.

27. Mori E, Ishikawa M, Kato T, Kazui H, Miyake H, Miyajima M, et al. Guidelines for management of idiopathic normal pressure hydrocephalus: second edition. Neurol Med Chir. 2012;52(11):775-809; doi: 10.2176/ nmc.52.775.

28. Agostini V, Lanotte M, Carlone M, Campagnoli M, Azzolin I, Scarafia R, et al. Instrumented gait analysis for an objective pre-/postassessment of tap test in normal pressure hydrocephalus. Arch Phys Med Rehabil. 2015;96(7):1235-1241; doi: 10.1016/j.apmr.2015.02.014.

29. Portney LG, Watkins MP. Foundation of clinical research: applications to practice, $2^{\text {nd }}$ ed. Pearson; 2000.

30. Edwards P. Questionnaires in clinical trials: guidelines for optimal design and administration. Trials. 2010;11:2; doi: 10.1186/1745-6215-11-2.

31. Snyder CF, Watson ME, Jackson JD, Cella D, Halyard MY. Patient-reported outcome instrument selection: designing a measurement strategy. Value Health. 2007; 10(Suppl. 2):S76-S85; doi: 10.1111/j.1524-4733.2007. 00270.x.

32. Tang A, Eng JJ, Rand D. Relationship between perceived and measured changes in walking after stroke. J Neurol Phys Ther. 2012;36(3):115-121; doi: 10.1097/ NPT.0b013e318262dbd0.

33. Herssens N, Verbecque E, Hallemans A, Vereeck L, Van Rompaey V, Saeys W. Do spatiotemporal param- eters and gait variability differ across the lifespan of healthy adults? A systematic review. Gait Posture. 2018;64:181-190; doi:10.1016/j.gaitpost.2018.06.012.

34. Malm J, Graff-Radford NR, Ishikawa M, Kristensen $\mathrm{B}$, Leinonen V, Mori E, et al. Influence of comorbidities in idiopathic normal pressure hydrocephalus research and clinical care. A report of the ISHCSF task force on comorbidities in INPH. Fluids Barriers CNS. 2013;10(1):22; doi: 10.1186/2045-8118-10-22.

35. Gallagher R, Marquez J, Osmotherly P. Gait and balance measures can identify change from a cerebrospinal fluid tap test in idiopathic normal pressure hydrocephalus. Arch Phys Med Rehabil. 2018;99(11): 2244-2250; doi: 10.1016/j.apmr.2018.03.018.

36. Lewek MD, Sykes R 3rd. Minimal detectable change for gait speed depends on baseline speed in individuals with chronic stroke. J Neurol Phys Ther. 2019;43(2): 122-127; doi: 10.1097/NPT.0000000000000257.

37. Ries JD, Echternach JL, Nof L, Gagnon Blodgett M. Test-retest reliability and minimal detectable change scores for the timed "up \& go" test, the six-minute walk test, and gait speed in people with Alzheimer disease. Phys Ther. 2009;89(6):569-579; doi: 10.2522/ptj.200 80258.

38. Almarwani M, Perera S, VanSwearingen JM, Sparto PJ, Brach JS. The test-retest reliability and minimal detectable change of spatial and temporal gait variability during usual over-ground walking for younger and older adults. Gait Posture. 2016;44:94-99; doi: 10.1016/j. gaitpost.2015.11.014.

\section{Appendix A. Self-reporting in changed gait ability after a spinal tap test}

\begin{tabular}{|c|c|c|c|c|c|c|c|}
\hline \multirow{2}{*}{ Item } & \multicolumn{7}{|c|}{ Score } \\
\hline & -3 & -2 & -1 & 0 & 1 & 2 & 3 \\
\hline Overall gait & $\begin{array}{l}\text { Extremely } \\
\text { worsened }\end{array}$ & $\begin{array}{c}\text { Much } \\
\text { worsened }\end{array}$ & $\begin{array}{c}\text { Little } \\
\text { worsened }\end{array}$ & No change & $\begin{array}{c}\text { Little } \\
\text { improved }\end{array}$ & $\begin{array}{c}\text { Much } \\
\text { improved }\end{array}$ & $\begin{array}{l}\text { Extremely } \\
\text { improved }\end{array}$ \\
\hline Step length & $\begin{array}{l}\text { Extremely } \\
\text { decreased }\end{array}$ & $\begin{array}{c}\text { Much } \\
\text { decreased }\end{array}$ & $\begin{array}{c}\text { Little } \\
\text { decreased }\end{array}$ & No change & $\begin{array}{c}\text { Little } \\
\text { increased }\end{array}$ & $\begin{array}{c}\text { Much } \\
\text { increased }\end{array}$ & $\begin{array}{l}\text { Extremely } \\
\text { increased }\end{array}$ \\
\hline Step time & $\begin{array}{l}\text { Extremely } \\
\text { worsened }\end{array}$ & $\begin{array}{c}\text { Much } \\
\text { worsened }\end{array}$ & $\begin{array}{c}\text { Little } \\
\text { worsened }\end{array}$ & No change & $\begin{array}{c}\text { Little } \\
\text { improved }\end{array}$ & $\begin{array}{c}\text { Much } \\
\text { improved }\end{array}$ & $\begin{array}{l}\text { Extremely } \\
\text { improved }\end{array}$ \\
\hline Gait speed & $\begin{array}{l}\text { Extremely } \\
\text { decreased }\end{array}$ & $\begin{array}{c}\text { Much } \\
\text { decreased }\end{array}$ & $\begin{array}{c}\text { Little } \\
\text { decreased }\end{array}$ & No change & $\begin{array}{c}\text { Little } \\
\text { increased }\end{array}$ & $\begin{array}{c}\text { Much } \\
\text { increased }\end{array}$ & $\begin{array}{l}\text { Extremely } \\
\text { increased }\end{array}$ \\
\hline
\end{tabular}

